\title{
MECHANICAL PROPERTIES OF PRESTRESSING STRANDS AND HOW THEY TEND TO CHANGE UNDER THERMO-MECHANICAL TREATMENT
}

\author{
A. G. Korchunov¹, M. A. Polyakova ${ }^{1}$, D. V. Konstantinov ${ }^{1}$, M. Dabalá \\ 1 Nosov Magnitogorsk State Technical University (Magnitogorsk, Russia) \\ 2 University of Padova (Padova, Italy)
}

E-mail: international@magtu.ru; m.polyakova@magtu.ru; magstu.international@gmail.com; manuele.dabala@unipd.it

\begin{tabular}{|c|c|}
\hline AUTHOR'S INFO & A B S T RACT \\
\hline $\begin{array}{l}\text { A. G. Korchunov, Dr. Eng., Prof., Vice-Rector } \\
\text { for International Affairs } \\
\text { M. A. Polyakova, Dr. Eng., Prof., Dept. of Material } \\
\text { Processing Technologies } \\
\text { D. V. Konstantinov, Cand. Eng. } \\
\text { M. Dabalá, Dr. Eng., Prof., Dept. of Industrial } \\
\text { Engineering }\end{array}$ & $\begin{array}{l}\text { This paper examines the mechanical properties of high-strength }(1,770 \mathrm{MPa}) 7 \text {-wire } \\
\text { prestressing strands and how they tend to change under thermo-mechanical treat- } \\
\text { ment involving short-term induction tempering under high tension. The change } \\
\text { dynamics of the following properties was monitored for } 12.5 \mathrm{~mm} \text { strands: tensile } \\
\text { strength, yield strength, full elongation at maximum tension force and modulus of } \\
\text { elasticity in the temperature range from } 360 \text { to } 400{ }^{\circ} \mathrm{C} \text {, the process speed range from } \\
50 \text { to } 65 \mathrm{~m} / \mathrm{min} \text {, and at the tension force of } 64 \mathrm{kN} \text {. The authors found a quantita- } \\
\text { tive increase of the mechanical properties of prestressing strands for all the studied } \\
\text { regimes of thermo-mechanical treatment. Thermo-mechanical treatment resulted in }\end{array}$ \\
\hline $\begin{array}{l}\text { Key words: } \\
\text { Prestressing strands, high-carbon steel, thermo-mechanical } \\
\text { treatment, mechanical properties, experimental study. }\end{array}$ & $\begin{array}{l}\text { a significant growth in yield strength }- \text { from } 28 \text { to } 36 \% \text {, and in full elongation at } \\
\text { maximum tension force, which demonstrated a higher than double growth. The paper } \\
\text { shows how the temperature and rate of thermo-mechanical processing influence the } \\
\text { mechanical properties of prestressing strands and their change dynamics. }\end{array}$ \\
\hline
\end{tabular}

\section{Introduction}

Prestressing strands are a high-technology product of the metalware industry that is used in heavy-duty pre- and post-stressed concrete structures, as well as in the construction of bridges, nuclear power plants, airports, tunnels, transport infrastructure, residential buildings, heating, power and water supply and water disposal systems.

Of great interest is the sector of stabilized prestressing steel strands, which are produced per extremely similar standards in many developed countries and which find application almost worldwide. For the most part, such prestressing strands are used in the production of prestressed reinforced concrete structures. The use of prestressing strands in concrete helps to significantly reduce the amount of steel reinforcement used and thus reduce the cost of reinforced concrete components while enhancing their quality [1].

The most common type of product, both in terms of production output and application scope, includes spiral stabilized prestressing 7-wire strands, in which six wires are spun around a core wire in one layer. For a combination of inherent properties and related production and application factors, strands of this design have been recognized as the most efficient type of high-strength prestressed steel strands.

In the world today, one can find quite a number of practically identical standards specifying the dimensions and mechanical properties of prestressing strands. A high degree of convergence between the standards can be attributed to both the use of efficient construction processes and a great similarity of equipment supplied by different manufacturers. In the Russian Federation, the production of stabilized prestressing strands is regulated by GOST R 53772-2010, whereas abroad the European standard pr EN 10138-3:2006 applies.

Specific aspects of production and application of prestressing strands for prestressed structures are the subject of numerous theoretical and experimental research papers [2-11]. There are ongoing studies that are looking at new production methods to enhance the mechanical properties of prestressing strands designed for application in extreme conditions. For example, researchers obtained a prestressing strand with the strength exceeding 2,100 MPa [12], which makes it applicable in prestressed reinforced concrete structures designed for seismic loads.

The process of cold drawing of patented steel under high strain degree followed by stranding and thermomechanical treatment is widely used in the production of high-strength prestressing strands. As a result of such processing, steel acquires a ferrite-cementite structure with an interlamellar spacing of $0.1-0.2 \mu \mathrm{m}$, and the

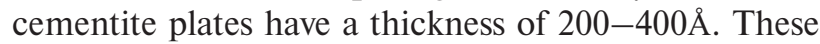
parameters ensure high strength and plasticity of strands. To eliminate spinning stresses and ensure high fatigue and relaxation resistance, prestressing strands are subjected to further thermo-mechanical treatment (TMT) or stabilization. The most advanced TMT process implemented on modern stabilization lines involves short-term induction tempering in the temperature range of $250-420^{\circ} \mathrm{C}$ under tension. The tensile stresses applied during treatment can reach $30-70 \%$ of the strand's tensile strength. 
The point of the stabilization process is to slightly deform hardened steel at temperatures below the recrystallization temperature. A combination of mechanical stresses and tempering ensures high elasticity and rheological properties together with high plasticity of metal. Metal becomes more relaxation resistant and retains this property over time without any major changes. The author of the paper [13] believes that at the basis of thermomechanical treatment lie processes related to the formation of pre-defined dislocation structure. According to another viewpoint, the enhanced relaxation properties resultant from TMT are mainly due to strain age-hardening [14]. The authors of the papers [15-18] attribute the changing mechanical properties of high-strength prestressing components to stress redistribution in steel under thermo-mechanical treatment.

Irrespective of the fact that the process of in-line stabilization and stranding has become the main and practically the only process of thermo-mechanical treatment applicable to prestressing strands on a global scale, there are many aspects related to this type of processing and the resultant mechanical performance that are yet to be studied more thoroughly. Researchers are also at variance about the effect produced by different TMT regimes on the mechanical properties of prestressing strands after stranding.

It is to be noted that, in a multi-stage process flow related to the production of prestressing strands, each operation has a certain potential to impact the mechanical properties of the product and contributes to obtaining the required quality of the final product. From this perspective, the process of thermo-mechanical treatment is of great importance as a process defining the final properties.

The aim of this research is to carry out a series of experiments to understand the effect produced by different TMT regimes on the mechanical properties of prestressing strands designed for prestressed reinforced concrete structures.

\section{Materials and Methods}

This paper examines a 7 -wire prestressing strand with the diameter of $12.5 \mathrm{~mm}$ and the strength of $1,770 \mathrm{MPa}$ made of high-carbon steel grade 80 . The chemical composition and mechanical properties of the initial wire rods are given in Table 1.

The prestressing strand was produced with the help of the following production operations: quality control of the initial $11.0 \mathrm{~mm}$ wire rod; patenting; surface preparation; multiple cold drawing of the core wire and the wires spun around it with the total strain degree reaching $86 \%$; stranding in a wire rope closing machine; thermo-mechanical treatment (TMT) in a stabilization line; cooling; coiling; and quality control of the final strand.

The stabilization line comprised three tandem $1.0 \mathrm{~m}$ long induction heaters. To understand how different TMT regimes would change the mechanical properties of the final strands, the researchers would vary the speed of the

\begin{tabular}{|c|c|c|c|c|c|c|c|c|}
\hline \multicolumn{6}{|c|}{ Content of elements, \% } & \multicolumn{3}{|c|}{ Mechanical properties } \\
\hline C & $\mathrm{Mn}$ & Si & $\mathrm{Cr}$ & $\mathrm{Ni}$ & V & $\begin{array}{c}\text { Tensile } \\
\text { strength } \\
\sigma_{\mathrm{B}}, \mathrm{MPa}\end{array}$ & $\begin{array}{c}\text { Reduc- } \\
\text { tion of } \\
\text { area } \psi, \%\end{array}$ & $\begin{array}{c}\text { Elongation } \\
\text { at rupture } \\
\quad \delta, \% \\
\end{array}$ \\
\hline 0.80 & 0.48 & 0.28 & 0.05 & 0.02 & 0.11 & 1050 & 27 & 11 \\
\hline
\end{tabular}

\begin{tabular}{|c|c|c|c|}
\hline \multicolumn{4}{|c|}{$\begin{array}{l}\text { Table 2. Experimental regimes of thermomechanical } \\
\text { treatment (TMT) }\end{array}$} \\
\hline TMT regime & Line speed, $\mathrm{m} / \mathrm{min}$ & Temperature, ${ }^{\circ} \mathrm{C}$ & Tension force, $\mathrm{kN}$ \\
\hline $50 / 360$ & 50 & 360 & \multirow{6}{*}{64} \\
\hline $50 / 380$ & 50 & 380 & \\
\hline $50 / 400$ & 50 & 400 & \\
\hline $65 / 360$ & 65 & 360 & \\
\hline $65 / 380$ & 65 & 380 & \\
\hline $65 / 400$ & 65 & 400 & \\
\hline Idle mode & No inducti & $n$ heat, minimal ter & sion force \\
\hline
\end{tabular}

stabilization line and the heating temperature applied. At the same time, the tension force of the stabilization line was at $64 \mathrm{kN}$ and remained the same throughout the experiment. The induction heat temperature applied varied from 360 to $400{ }^{\circ} \mathrm{C}$, and the process speed varied from 50 to $65 \mathrm{~m} / \mathrm{min}$. To achieve the goal of the experiment, the strand was treated in idle mode with the induction heaters being disabled and at minimal tension force.

The values of the varied process parameters were selected allowing for the technical characteristics of the stabilization line designed to implement the studied process, as well as with the purpose of maintaining the cost-effectiveness of the production. Table 2 describes the experimental TMT regimes applied.

The microstructure of the specimens of prestressing strands was studied per GOST 8233: Steel. Microstructure standards. A detailed microstructural analysis was carried out on the JSM 6490 LV scanning electron microscope. Both core wires and spun wires were analyzed for each TMT regime. The Thixomet PRO image analyzer was used to analyze certain microstructural parameters.

The mechanical properties of the specimens were studied per GOST R 53772-2010: Reinforced steel lowrelaxation 7-wire strands. Specifications, on the LFM-400 Walter+Bai AG electromechanical test machine. Four 1 $\mathrm{m}$ long specimens were selected for each of the studied TMT regimes. Specimens in aggregate state were used for tensile tests. The dynamic microhardness of the specimens was studied with the help of the SHIMADZU DUH-211S ultra micro hardness tester per GOST R 8.748 (ISO 145771:2002): State system for ensuring the uniformity of measurements. Metallic materials. Instrumented indentation test for hardness and materials parameters. Part 1. Test method.

\section{Results and Discussion}

Through the microstructural analysis of steel, it was established that, in idle mode with no induction heat ap- 

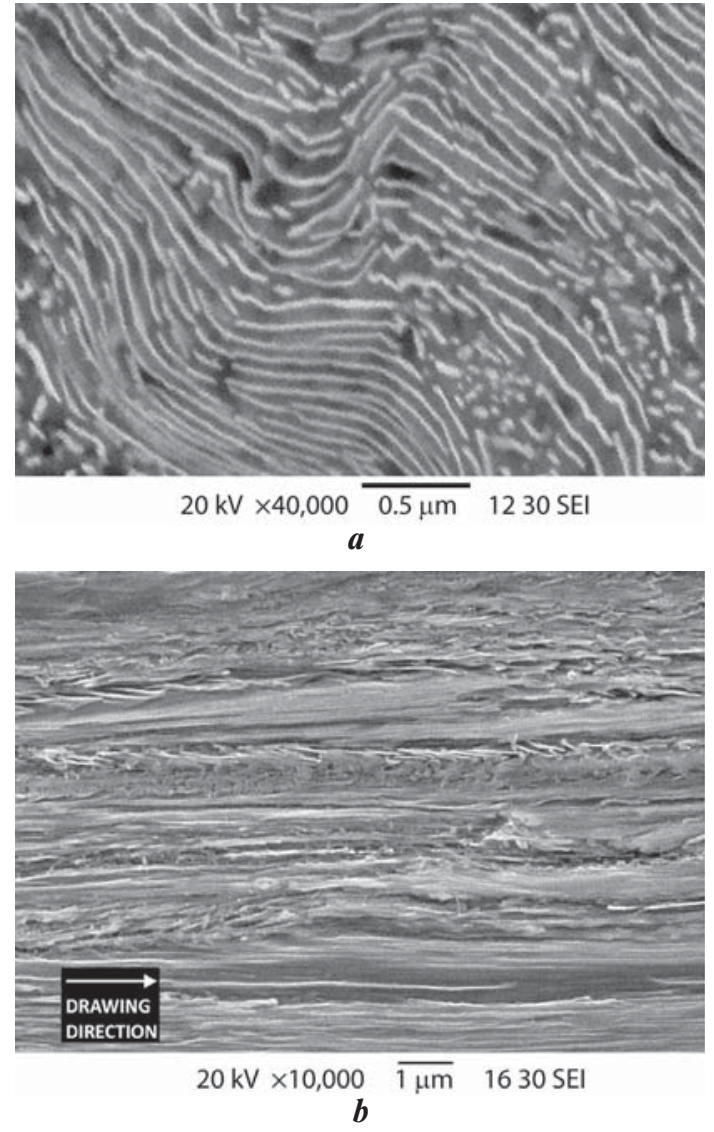

Fig. 1. Fine structure of FCM in the microstructure of steel in transverse (a) and longitudinal (b) directions following treatment in idle mode

plied, the microstructure in the centre of the cross-section of the core wire and the spun wires is comprised of a ferrite-carbide mixture (FCM) with the average thickness of cementite plates being $0.047 \mu \mathrm{m}$ (Fig. 1, a). One can see a distinct vortex-like structure of the FCM colonies, and the cementite plates are severely deformed and partially destroyed. This is a typical microstructure of patented steel that was subjected to multiple cold drawing with high strain degree (over 80\%).

The microstructural analysis of steel specimens in longitudinal direction (Fig. 1, b) helped identify a typical deformation texture that formed in the drawing direction due to high total strain degree.
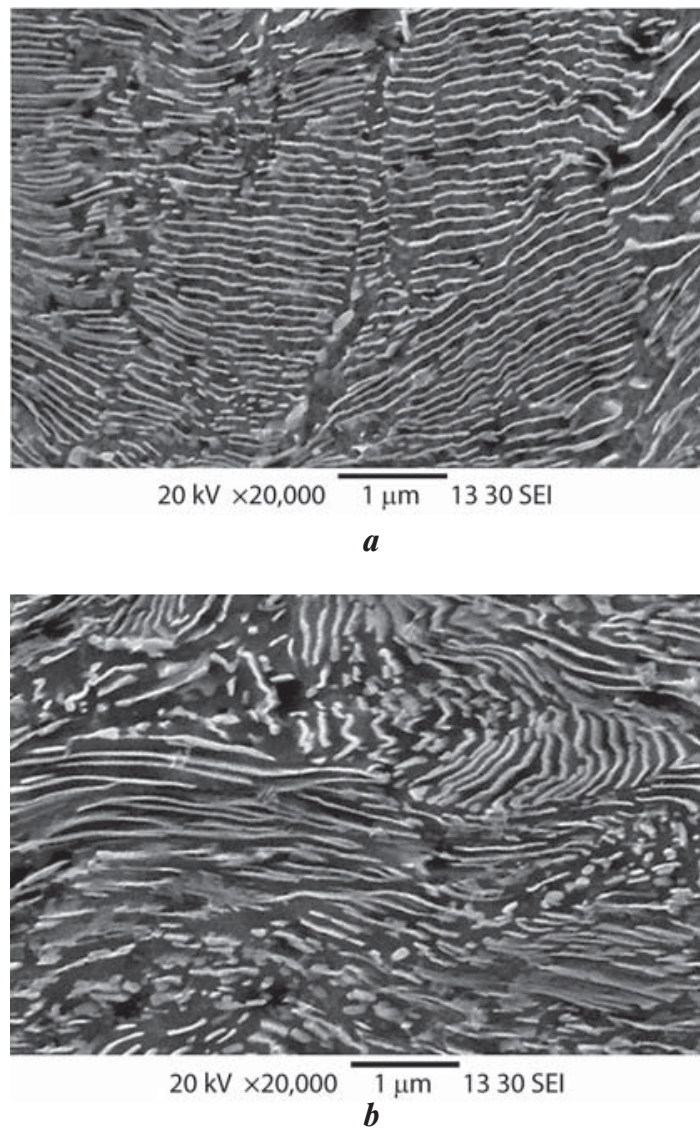

Fig. 3. Fragments of cementite plates: Early stages of coagulation following the $50 / 400(a)$ and $65 / 400(b)$ regimes of thermo-mechanical treatment (see Table 2)

Deformed cementite plates of FCM (Fig. 2, a ), a vortex-like structure of the FCM colonies (Fig. 2, b) and partially destroyed cementite plates (Fig. 2, c) can also be observed in the microstructure of steel after thermomechanical treatment.

It is also to be noted that early stages of coagulation of the cementite plate fragments were observed during thermo-mechanical treatment when the steel was heated to $400{ }^{\circ} \mathrm{C}$ (Fig. 3).

The qualitative and quantitative analysis of microstructure performed with a scanning electron microscope showed that, in the studied range of speeds and heating temperatures, thermo-mechanical treatment did not lead

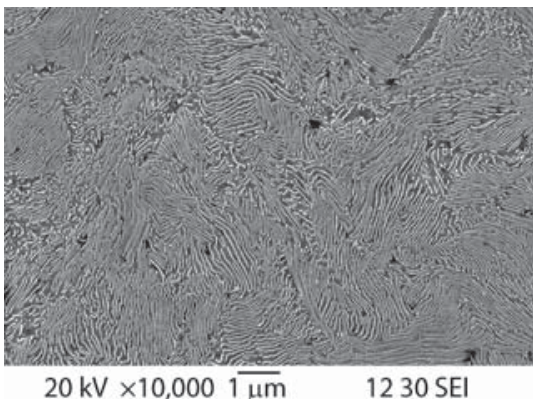

a
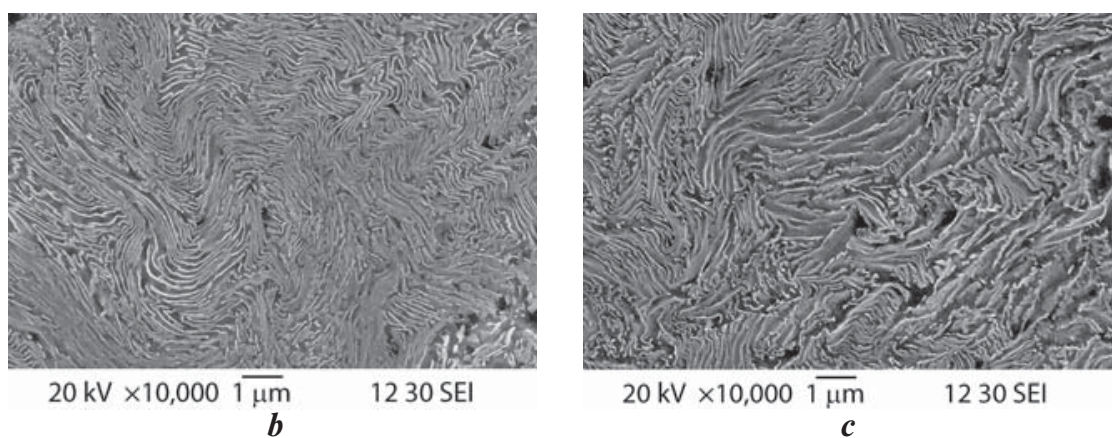

Fig. 2. Fine structure of FCM in the microstructure of steel following the 50/380 regime of thermo-mechanical treatment (see Table 2) 


\begin{tabular}{|c|c|c|c|c|c|c|c|}
\hline \multirow[t]{2}{*}{ Mechanical properties of strand } & \multicolumn{7}{|c|}{$\begin{array}{l}\text { Regimes of thermo-mechanical treatment } \\
\text { (speed/temperature, } \mathrm{m} / \mathrm{min} /{ }^{\circ} \mathrm{C} \text { ) }\end{array}$} \\
\hline & Idle mode & $50 / 360$ & $50 / 380$ & $50 / 400$ & $65 / 360$ & $65 / 380$ & $65 / 400$ \\
\hline $\begin{array}{l}\text { Maximum tension force } \\
\text { at rupture, } \mathrm{kN}\end{array}$ & 158.25 & 167.67 & 169.41 & 166.15 & 168.55 & 167.4 & 166.72 \\
\hline $\begin{array}{l}\text { Tension force at } 0.1 \% \text { yield } \\
\text { strength, } \mathrm{kN}\end{array}$ & 108.84 & 145.65 & 148.52 & 139.88 & 147.61 & 145.27 & 143.39 \\
\hline Tensile strength $\sigma_{\mathrm{B}}, \mathrm{MPa}$ & 1702.18 & 1803.47 & 1822.2 & 1787.09 & 1812.95 & 1800.57 & 1793.26 \\
\hline Yield strength $\sigma_{0.1}, \mathrm{MPa}$ & 1170.66 & 1566.57 & 1597.47 & 1504.6 & 1587.73 & 1562.53 & 1542.33 \\
\hline$\sigma_{0.1 /} \sigma_{\text {B ratio }}$ & 0.69 & 0.87 & 0.88 & 0.84 & 0.88 & 0.87 & 0.86 \\
\hline $\begin{array}{l}\text { Full elongation at maximum } \\
\text { tension force } \delta_{\max } \%\end{array}$ & 1.94 & 4.26 & 4.32 & 4.62 & 4.01 & 4.10 & 4.18 \\
\hline Modulus of elasticity $E, \mathrm{GPa}$ & 187.34 & 198.6 & 196.78 & 198.62 & 196.62 & 195.09 & 196.96 \\
\hline
\end{tabular}

\begin{tabular}{|c|c|c|c|c|c|}
\hline \multicolumn{2}{|c|}{ Table 4. Mean values of the steel parameters obtained during dynamic microhardness testing } \\
\hline $\begin{array}{c}\text { TMT regime (speed/ } \\
\left.\text { temperature, } \mathrm{m} / \mathrm{min} /{ }^{\circ} \mathrm{C}\right)\end{array}$ & $\begin{array}{c}\text { Martens hardness, } \\
\text { HMT115 }\end{array}$ & $\begin{array}{c}\text { Martens hardness, } \\
\text { HMs }\end{array}$ & $\begin{array}{c}\text { Indentation hardness, } \\
\text { HIT }\end{array}$ & $\begin{array}{c}\text { Indentation creep } \\
\text { CIT, \% }\end{array}$ & $\begin{array}{c}\text { Elastic component during } \\
\text { indentation } \eta \mathrm{IT}, \%\end{array}$ \\
\hline Idle mode & 1970 & 1172 & 4309 & 2.2 & 46 \\
\hline $50 / 360$ & 2449 & 2191 & 3747 & 2.8 & 33 \\
\hline $50 / 380$ & 2797 & 2287 & 4456 & 2.5 & 34 \\
\hline $50 / 400$ & 2216 & 1859 & 3685 & 2.0 & 40 \\
\hline $65 / 360$ & 3208 & 2637 & 4922 & 2.9 & 30 \\
\hline $65 / 380$ & 2242 & 1697 & 3797 & 3.8 & 38 \\
\hline $65 / 400$ & 1965 & 1520 & 3266 & 4.7 & 36 \\
\hline
\end{tabular}

to any significant changes in the steel microstructure obtained earlier by patenting and cold drawing of wires. In different TMT regimes, the mean values of the cementite plate thickness and the deformation texture remain the same as in the specimens of the prestressing strand produced in idle mode.

Table 3 contains the results of testing of prestressing strands after application of different TMT regimes. The graphs representing the test results are given in Fig. 4.

Table 4 shows mean values of the steel parameters obtained during indentation tests performed on crosssectional specimens of spun wires after application of different TMT regimes.

Analysis of the mechanical properties of prestressing strands processed in different TMT regimes in comparison with the strand processed in idle mode indicated that all the analyzed mechanical properties tend to improve in various degrees in all the studied regimes (Fig. 4). An absolute increase in tensile strength $\sigma_{B}$ is from 100 to $120 \mathrm{MPa}$ or $5-7 \%$ (Fig. 4, a). The parameters of yield strength $\sigma_{0.1}$ and full elongation at maximum tension force $\delta_{\max }$ were found to be most sensitive to thermo-mechanical treatment. The yield strength $\sigma_{0.1}$ increased by 28 to $36 \%$. The maximum absolute increase of $427 \mathrm{MPa}$ was registered for the heating temperature of $380^{\circ} \mathrm{C}$ and the processing speed of $50 \mathrm{~m} / \mathrm{min}$ (Fig. $\mathbf{4}, \boldsymbol{b})$. The full elongation at maximum tension force $\delta_{\max }$ demonstrated a higher than double increase in all the TMT regimes (Fig. $4, \boldsymbol{c}$ ). The modulus of elasticity $E$ increased by $4-6 \%$. The increase of the representative $\sigma_{0.1} / \sigma_{\mathrm{B}}$ ratio was in the range of 21 to $27 \%$.

Considering the above mentioned slight changes in the microstructural parameters of steel under thermo-mechanical treatment, the enhanced mechanical

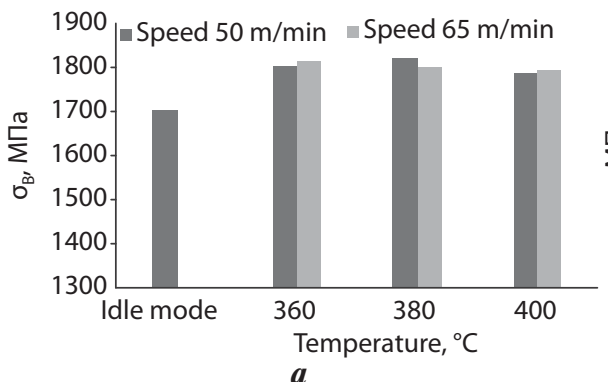

$\boldsymbol{a}$

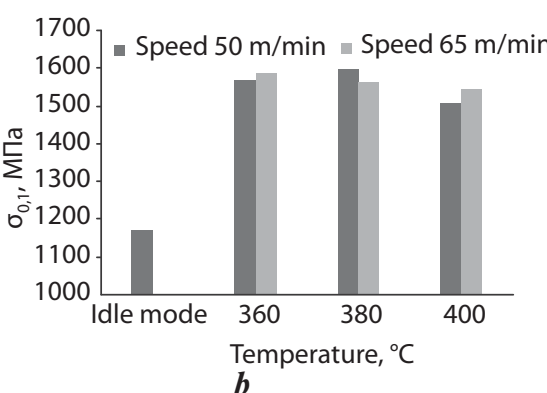

$\boldsymbol{b}$

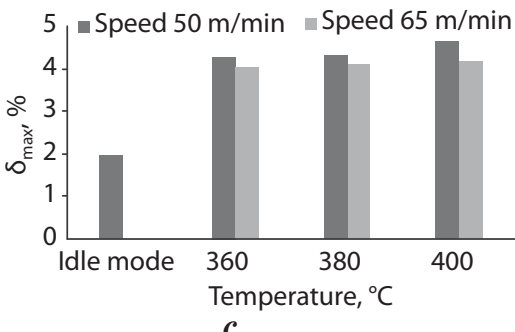

Fig. 4. Mechanical properties of prestressing strands and how they tend to change in different TMT regimes 
properties of the strands can probably be attributed to a significant redistribution of residual spinning stresses during treatment and an improved uniformity of the material properties. Fig. $\mathbf{5}$ shows hardness values measured in the cross-section of spun wires sampled from a strand produced in the idle mode of the stabilization line and after thermo-mechanical treatment at the temperature of $380^{\circ} \mathrm{C}$ and the process speed of $50 \mathrm{~m} / \mathrm{min}$. One can see that after thermo-mechanical treatment the distribution of hardness across the section of the spun wire becomes much more even.

It was found that the TMT temperature played a major role governing the dynamics of changing mechanical properties, whereas the TMT speed would become a more noticeable factor as the temperature would rise. Significant changes in the mechanical behaviour of strands were observed when the temperature would reach $400{ }^{\circ} \mathrm{C}$, which may be linked to the early stages of coagulation of the cementite plate fragments in the microstructure caused by the rising temperature (see Fig. 3).

Thus, as the temperature would rise from 360 to $400{ }^{\circ} \mathrm{C}$, the full elongation at maximum tension force $\delta_{\max }$ tended to slightly rise (see Fig. 4). At the same time, the parameters of tensile strength and yield strength $\sigma_{0.1}$ would slightly decrease. In the temperature range of 360 $380^{\circ} \mathrm{C}$, the increase of speed from 50 to $65 \mathrm{~m} / \mathrm{min}$ would not produce any noticeable impact on the mechanical properties of strands.

For the specimens of strands that were processed at the speed of $50 \mathrm{~m} / \mathrm{min}$, the maximum microhardness param-
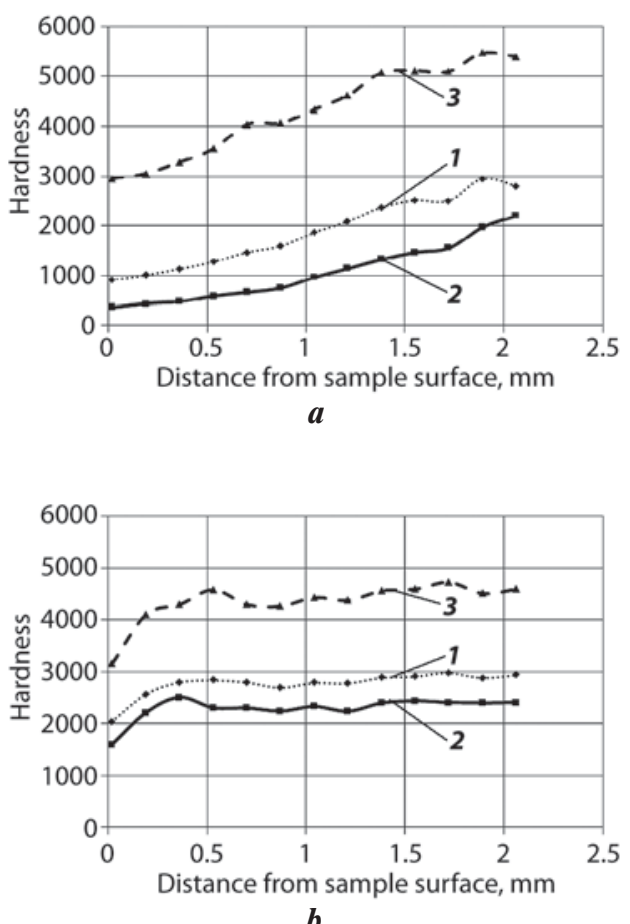

Fig. 5. Distribution of hardness across the section of the spun wires:

$a$ - Idle mode; $\sigma-50 / 380$ regime of TMT; 1-HMT; 2-HMs; 3 - HIT eters of spun wires (HMT115, HMS, HIT) were reached when they were heated to $360{ }^{\circ} \mathrm{C}$, whereas the heating temperature of $400{ }^{\circ} \mathrm{C}$ is associated with minimum microhardness. When the speed is increased to $65 \mathrm{~m} / \mathrm{min}$ and the heating temperature is raised from 360 to $400{ }^{\circ} \mathrm{C}$, the maximum microhardness parameters HMT115, HMS, HIT in spun wires slightly drop. At the same time, the HMT115, HMS and HIT values are higher than the ones for the idle mode specimen (see Table 4).

Special attention should be given to the relationship between the processing speed and the indentation creep CIT, \% (see Table 4). Analysis indicates that, for the TMT speed of $50 \mathrm{~m} / \mathrm{min}$, a rising heating temperature does not lead to any noticeable change in the indentation creep CIT, \%. However, at the speed of $65 \mathrm{~m} / \mathrm{min}$ as the heating temperature rises, the indentation creep demonstrates a higher than double increase compared with the idle mode specimen.

\section{Conclusions}

A series of experimental studies has been conducted to understand the effect produced by different TMT regimes on the mechanical properties of high-strength $(1,770 \mathrm{MPa}) 12.5 \mathrm{~mm} 7$-wire prestressing strands. For the purpose of the experiments, the following parameters of the stabilization line were used: induction heat temperature - from 360 to $400{ }^{\circ} \mathrm{C}$, process speed - from 50 to $65 \mathrm{~m} / \mathrm{min}$, tension force $-64 \mathrm{kN}$. The following conclusions can be drawn upon analysis of the results:

1. In the studied range of speeds and heating temperatures applied on the stabilization line, thermo-mechanical treatment does not lead to any significant changes in the steel microstructure produced by patenting and cold drawing. Deformed cementite plates of the ferritecarbide mixture with the thickness of up to $0.047 \mu \mathrm{m}$, a vortex-like structure of the FCM colonies and partially destroyed cementite plates can be observed in the microstructure of steel. When the temperature reaches $400{ }^{\circ} \mathrm{C}$, early stages of coagulation of the FCM cementite plate fragments can be observed.

2. In reference to the initial state of a laid strand, all the studied TMT regimes were associated with increased values of the tensile strength $\sigma_{B}$, yield strength $\sigma_{0.1}$, full elongation at maximum tension force $\delta_{\max }$ and modulus of elasticity $E$. A quantitative increase of the mechanical properties of prestressing strands was identified as a result of thermo-mechanical treatment. The most noticeable increase was observed with the yield strength $\sigma_{0.1}-$ from 28 to $36 \%$, and the full elongation at maximum tension force $\delta_{\max }-$ a higher than double rise, which is true for all the TMT regimes.

3. The changing process temperature was found to produce a more noticeable effect on the mechanical behaviour of prestressing strands. The effect of the process speed becomes more pronounced as the temperature reaches $400{ }^{\circ} \mathrm{C}$. 
4. The best combination of mechanical properties in prestressing strands can be obtained at the induction heat temperature of $380{ }^{\circ} \mathrm{C}$ and the stabilization line speed of $50 \mathrm{~m} / \mathrm{min}$. It was observed that these parameters were associated with the most even distribution of microhardness in the cross-section of the spun wires.

This research was funded by the Ministry of Science and Higher Education of the Russian Federation as part of a comprehensive project aimed at establishing a hightechnology production line with support from a higher educational institution (Contract No. 02.G25.31.0178 dated 01/12/2015; No. MK204895 dated 27/07/2015).

The authors would like to thank the foundation Fondazione Cariparo for their support of the Visiting Program TIP-STEP project.

\section{REFERENCES}

1. Madatyan S. A. The current level of requirements to prestressing strands. Beton i zhelezobeton. 2005. No. 1. pp. 8-10.

2. Egorov V. D., Voronina V. S. Production of prestressing strands in a stress-relieved state. Stal. 1983. No. 3. pp. 65-66.

3. Costello G. A. Theory of wire rope. Second edition. New York: Springer, 1997. $123 \mathrm{p}$

4. Feyrer K. Wire ropes: tension, endurance, reliability. Berlin-Heidelberg-New York: Springer, 2007. $322 p$

5. Luciano Jacinto, Manuel Pipa, LuHs Oliveira Santos. Probabilistic models for mechanical properties of prestressing strands. Construction and Building Materials. 2012. Vol. 36. pp. 84-89.

6. Yusuf Aytaç Onur. Experimental and theoretical investigation of prestressing steel strand subjected to tensile load. International Journal of Mechanical Sciences. 2016. Vol. 118. pp. 91-100.

7. Obaydullah M., Mohd Zamin Jumaat, Alengaram U. J., Mahfuz ud Darain Kh., Nazmul Huda Md., Akter Hosen Md. Prestressing of NSM steel strands to enhance the structural performance of prestressed concrete beams. Construction and Building Materials. 2016. Vol. 129. pp. 289-301.

8. Mikhaylov K. V. The challenges faced by domestic construction science in the area of rebars and prestressed reinforced concrete structures. Beton i zhelezobeton. 2004. No. 2. pp. 3-5.

9. Chukin M. V., Gun G. S., Korchunov A. G., Polyakova M. A. Prospects of production of high-strength steel reinforced bars made of highcarbon steels. Chernye Metally. 2012. No. 12. pp. 8-16.

10. Chabbi L. Simulation of microstructure and mechanical properties in section rolling. Chernye Metally. 2017. No. 9. pp. 57-62.

11. Korchunov A. G., Gun G. S., Shiryaev O. P., Pivovarova K. G. Study of structural transformation of hot-rolled carbon billets for highstrength ropes for responsible applications via the method of thermal analysis. CIS Iron and Steel Review. 2017. Vol. 13. pp. 38-40.

12. Jin Kook Kim, Jeong-Su Kim, and Seung Hee Kwon. Mechanical Properties of a New Prestressing Strand with Ultimate Strength of 2160 MPa. KSCE Journal of Civil Engineering. 2014. Vol. 18(2). pp. 607-615.

13. Yukhvets I. A. Production of high-strength reinforcement wire. Moscow : Metallurgiya, 1973. $264 \mathrm{p}$.

14. Babich V. K., Gul I. E., Dolzhenkov I. I. Strain ageing of steel. Moscow : Metallurgiya, 1972. 320 p.

15. Caballero L., Atienza J. M., Elices M. Thermo-mechanical treatment effects on stress relaxation and hydrogen embrittlement of colddrawn eutectoid steels. Metals and Materials International. Vol. 17, No. 6. 2011. pp. 899-910.

16. Ruiz-Hervias, V. Luzin, H. Prask, T. Gnaeupel-Herold, M. Elices. Effect of thermo-mechanical treatments on residual stresses measured by neutron diffraction in cold-drawn steel rods. Materials Science and Engineering A. 435-436. 2006. pp 725-735.

17. Zeren A., Zeren M. Stress relaxation properties of prestressed steel wires. Journal of Materials Processing Technology. 2003. No. 141. pp. 86-92.

18. Korchunov A. G., Tereshchenko N. A., Efimova Yu. Yu., Dabalà M., Dolgiy D. K. The mechanical properties of cold-drawn eutectoid steel and how they change under thermo-mechanical treatment. Vestnik of Nosov Magnitogorsk State Technical University. 2014. No. 1. pp. 58-62.

\section{A. Bocharov, V. A. Ignatkina}

\section{Technology of mineral processing}

- Mineral raw materials base

- Technology of rare metals processing

- TECHNOLOGY OF NON-FERROUS METALS PROCESSING

- Technology of RARE MEtals processing

- Processing of gold-bearing ores and alluvial deposits

- Processing of ferrous ores

- Processing of carbon group ores

- Processing of Mining-Chemical and NON-MEtallic RaW MATERIals

- Production organization and management on PROCESSING PLANTS

Реклама

Advertisement

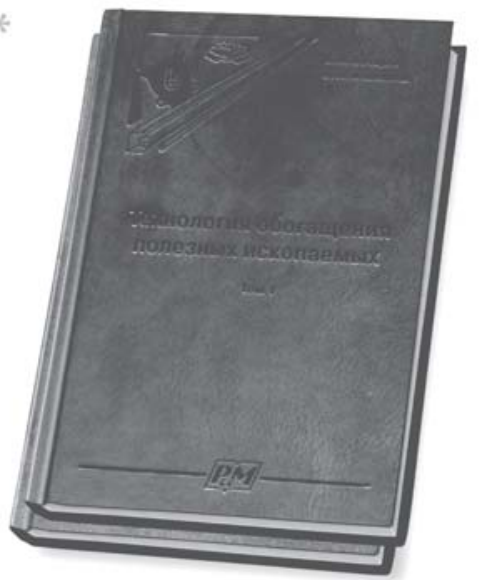

If you want order this book, you should send your request: P. O. Box 71, B-49, Moscow, 119049, Russia Phone + 7(495) 955-01-75 E-mail: books@rudmet.com Internet: http://www.rudmet.com 